\title{
Comparative Analysis of the Impacts on Operating Income of Power Grid Corporation after Implementing Straight-Powered or Self-Generation
}

\author{
Huiru Zhao ${ }^{1}$, Nana $\mathrm{Li}^{1}$, Huijuan $\mathrm{Jiang}^{1}$ and Guangjuan Chen ${ }^{2}$ \\ ${ }^{1}$ School of Economics and Management, North China Electric Power University \\ ${ }^{2}$ State Grid Shanxi Electric Power Corporation \\ nancyli1007@163.com
}

\begin{abstract}
Straight-powered for big users and self-generation power plants are the important measures to promote the electricity market reform in China. However, on the one hand, straight-powered for big users may carry some impacts on the management of power Grid Corporation, such as cost, revenue, etc. On the other hand, self-generation power plants will directly reduce the electricity sales of power Grid Corporation, which affects the operating income accordingly. Through analyzing the composition of income in power grid corporation, two models measuring the impacts on operating income after implementing straight-powered or self-generation are put forward. Meanwhile, an empirical study on the operating income effects of a power grid corporation is presented. The results show that straight-powered for big users and self-generation power plants make the corporation lose 0.00152 yuan per $k W h$ and 0.02 yuan per $k W h$, respectively. Obviously, the impact of implementing self-generation power plant is greater.
\end{abstract}

Keywords: Impact; Operation income; Straight-powered; Self-generation; Power Grid Corporation

\section{Introduction}

In order to optimal the allocation of power resources and break the monopoly pattern of the power grid enterprise, the straight-powered for big users and self-generation power plants are gradually carried on, so as to promote the development of an open electricity market [1]. The straight-powered for big users is an electricity purchasing mode of bilateral trade between large electricity users and power generation enterprises. While, the self-generation power plants are mainly constructed in energy intensive enterprises, which are established to solve the power shortage and reduce electricity cost of production [2].

However, the implement of straight-powered for big users and self-generation power plants may impact on the operation of power Grid Corporation. First of all, the power generation schedule would transform from the centralized decision-making to decentralized decision making, which significantly increase the complexity of power dispatching and coordination [3]. Obviously, the model of straight-powered for big users belongs to decentralized decision in nature, the behavior of market profit may produce an unexpected operation mode of power grid, which affect the security and reliability of the power grid $[4,5]$. Subsequently, with the development of the straight-powered for big users, the bilateral trade contract may fix the output pace of the generations. Unfortunately, the schedulable output may greatly narrow down, and the units participating in peak shaving would significantly reduce as well. The peak shaving resources in the power grid would be more nervous accordingly. Moreover, at the same time, the contract of straight-powered for big users would influence the reserve capacity of the generation units, which is used to regulate peak load on time. For this reason, in 
some extreme cases, the straight-powered for big users may cause a serious shortage of spare capacity of power grid scheduling. Besides, the bilateral contract of straightpowered for big users determines the maintenance time when generators can be overhauled to a large extent. What's more, because of the time-varying characteristics of the supply and demand and prices, contract delivery time difference will directly affect the purchasing cost of users and generating cost of power enterprises. At last, the electricity market out of straight-powered for big users would be affected simultaneously [6]. The cross subsidy costs undertaken by big users may shift to power Grid Corporation and other users, which increases the burden of enterprises and reduces the electricity sales. In addition, in order to reduce the production subsidy cost, this users would expand the scale of production and obtain the qualification of straight-powered, which contributes to the loss of power grid enterprise.

Through building the self-generation power plants, manufacturing enterprises could realize the comprehensive utilization of resources and the reduction of production cost. However, the safe operation of power grid would be threatened at some extent ${ }^{[7]}$. First of all, as the change of user requirements and regulations, self-generation power plants conduct start-stop adjustment. It is the uncertainty that is likely to cause obvious voltage flicker of distribution network. Meanwhile, owning to the sudden change of the output, the voltage control gear in the power plant may easily cause voltage flicker, which brings harmonic pollution to power system. Therefore, in order to maintain the normal operation of power system, the change of start-stop and output should be taken into consideration ${ }^{[8]}$. Namely, the operation of power grid is restricted by reason of the self-generation power plants. Secondly, under normal circumstances, since self-generation power plants do not receive the power from system, power Grid Corporation is always in the standby state. Therefore, the power grid corporation should strengthen the construction of power grid, so as to maintain a normal standby application. Besides, when self-generation power plants break down, the gap between peak load and valley load would become larger, which increases the peak shaving difficulty of power grid and reduce the reliability of the system.

On the other hand, from the perspective of management benefit, the implement of straight-powered for big users and self-generation power plants may impact on power Grid Corporation as well. After implementing the straight-powered, power grid corporation would reduce purchasing electric energy from power plants. Nevertheless, owning to the characteristic of transmission mechanism, electric energy is transmitted to customers through power grid. The power grid corporation still can obtain the transmission income. This shows that the business model and market shares of power Grid Corporation would change with the development of straight-powered mode. In addition, the self-generation power plants will permanently occupy the electricity market to some extent, the trading power and income of power Grid Corporation would decrease accordingly. As a result, it is necessary to calculate and compare the impacts on the operating income of power Grid Corporation after implementing straight-powered or selfgeneration, so as to guide the power market reform accurately.

\section{Impact Calculation Model for Straight-Powered for Big Users}

Under the mode of straight-powered for big users, big users for electricity would directly sign power purchase agreement with power Grid Corporation, which would result a reduction in electricity sales. Moreover, the transaction scale would change with the development of straight-powered mode, and the total cost, total income and transmission service charge would change as well. Above all, all these factors lead to an income reduction of power Grid Corporation after implementing straight-powered for big users. The calculation model of the impacts on the operating income of power grid corporation after implementing straight-powered for big users is shown as follows [9]: 
Step1:

The electricity income of big users before implementing straight-powered is:

$$
R=\sum_{j=110,220} \sum_{i=1}^{n_{j}}\left[R_{0, j, i}+\left(P_{j, i}-F-G\right) \times Q_{\mathrm{j}, i}\right]
$$

Where, $R$ denotes the electricity income of big users before implementing straightpowered; $R_{0, j, i}$ refers to the basic tariff; $P_{j, i}$ is the energy price for big users under the voltage classes of $j ; F$ represents the government funds and attached; $Q_{\mathrm{j}, i}$ is the direct supply power for big users under the voltage classes of $j ; G$ denotes the average power purchase price; $z$ is the voltage classes; $n_{j}$ is the number of big users under the voltage classes of $j$.

Step2:

Generally speaking, the transmission-distribution price for big users includes basic capacity price and electricity price [10]. Where, the basic electricity price is the same as the price of industrial electricity; the capacity price includes transmission cost and transmission loss for electricity. After implementing the mode of straight-powered, the income of power Grid Corporation from big users for electricity is [11]:

$$
R^{\prime}=\sum_{j=110,220} \sum_{i=1}^{\mathrm{n}_{\mathrm{j}}}\left(\mathrm{R}_{0, \mathrm{j}, i}+P_{\mathrm{j}, i} /\left(1-\delta_{j}\right) * Q_{\mathrm{j}, i}\right)
$$

Where, $P_{\mathrm{j}, i}$ ' denotes the electricity price of big users; $\delta_{j}$ represents the comprehensive line loss.

Step3:

In conclusion, the income changes of power Grid Corporation after implementing the mode of straight-powered is:

$$
\begin{aligned}
& \Delta R=R^{\prime}-R=\sum_{j=110,220} \sum_{i=1}^{n_{j}} P_{j, i}^{\prime} /(1-\delta) \times Q_{j, i}-\sum_{j=110,220} \sum_{i=1}^{n_{j}}\left(P_{j, i}-F-G\right) \times Q_{j, i} \\
& =\sum_{j=110,220} \sum_{i=1}^{n_{j}}\left(P_{j, i}^{\prime} /(1-\delta)-P_{j, i}+F+G\right) \times Q_{j, i}
\end{aligned}
$$

Step4:

In addition, the average reduction of income is shown as follows:

$$
\Delta P=\frac{\Delta R}{Q /\left(1-\delta^{\prime}\right)}
$$

Where, $Q$ denotes the total electricity consumption; $\delta^{\prime}$ refers to the accumulative line loss.

\section{Impact Calculation Model for Self-Generation Power Plant}

Since the electricity sales would decrease with the development of self-generation power plants, the income of power grid corporation would be affected as well [12]. The impact calculation model for the impacts on operating income of power Grid Corporation 
after implementing self-generation power plants is shown as below:

Step1:

The electricity income of big users for electricity before establishing self-generation power plant is:

$$
R=\sum_{i=1}^{n}\left[R_{0 i}+(P-G) Q_{i}\right]
$$

Where, $R$ denotes the electricity income of these users before establishing selfgeneration power plant; $R_{0 i}$ represents the basic tariff; $Q_{i}$ refers to the power consumption of different companies; $P$ denotes the sell electricity tariff; $G$ is the average power purchase price; $n$ denotes the number of self-generation power plants.

Step2:

When the generation capacity of self-generation power plants is smaller than electricity consumption, the income of power Grid Corporation is constituted by two parts: power supply income and system backup fee.

Therefore, the income of power Grid Corporation after implementing self-generation can be denoted as follows:

$$
R_{1}{ }^{\prime}=\sum_{i=1}^{u}\left[R_{0 i}+(P-G) Q_{g}+\left(B+P_{i}{ }^{\prime}\right) * Q_{z}\right]
$$

Where, $R_{0 i}$ is the basic tariff; $Q_{g}$ refers to the purchasing power of different companies; $B$ is the system backup price; $u$ denotes the plant number which the generating capacity is smaller than electricity consumption.

Step3:

Besides, when the generating capacity is larger than electricity consumption, the redundant power would be sold to power Grid Corporation. But, the system backup price is still imposed. What's more, the power supply may be insufficient sometimes in this kind of companies. For such situation [13], the income of power Gird Corporation is:

$$
R_{2}{ }^{\prime}=\sum_{i=u}^{n}\left[R_{0 i}+\left(B+P_{i}^{\prime}\right) * Q_{z}+\left(G-P_{l}\right) * Q_{s}+(P-G) Q_{g}\right]
$$

Where, $P_{l}$ denotes the temporary tariff, $Q_{s}$ refers to the on-grid energy.

Stpe4:

In conclusion, the income changes of power Grid Corporation after building selfgeneration power plants is:

$$
\begin{aligned}
& \Delta R_{z b}=R-\left(R_{1}{ }^{\prime}+R_{2}{ }^{\prime}\right) \\
& =\sum_{i=1}^{n}\left[R_{0 i}+(P-G) Q_{i}\right]-\sum_{i=1}^{u}\left[R_{0 i}+(P-G) Q_{g, i}+\left(B+P_{i}{ }^{\prime}\right) * Q_{z, i}\right] \\
& -\sum_{i=u}^{n}\left[R_{0 i}+\left(B+P_{i}{ }^{\prime}\right) * Q_{z, i}+\left(G-P_{i}\right) * Q_{s, j}+(P-G) Q_{g, i}\right] \\
& =\sum_{i=1}^{n}\left[(P-G) Q_{i}\right]-(P-G) \sum_{i=1}^{n} Q_{g}-\sum_{i=1}^{n}\left[\left(B+P_{i}^{\prime}\right) * Q_{z, i}\right]+\sum_{i=1}^{n}\left[\left(G-P_{i}\right) * Q_{s}\right]
\end{aligned}
$$


Step 5:

In addition, the average reduction of income is shown as follows:

$$
\Delta P=\frac{\Delta R_{z b}}{Q_{\text {total }}}
$$

\section{Empirical Analysis}

Taking Shanxi province electric power company as the empirical analysis object, the impacts on operating income after implementing straight-powered or self-generation are analyzed, according to relevant trade situation of electricity in Shanxi province.

(1) Analysis of straight-powered for big users

According to the electricity price data about straight-powered for big users in Shanxi province, main parameter values are shown in Table 1:

Table 1. Relevant Parameters about Straight-Powered

\begin{tabular}{|c|c|}
\hline Parameters & Values \\
\hline $\begin{array}{l}\text { Electricity price of transmission price } \\
\text { for } 110 \mathrm{KV} \text { voltage big users of straight- } \\
\text { powered }\end{array}$ & $P_{110, i}=64$ yuan $/ \mathrm{kWh}$ \\
\hline Trading power & $\sum Q_{110, i}=1981580000 \mathrm{kWh}$ \\
\hline $\begin{array}{l}\text { Electricity price of transmission price } \\
\text { for } 220 \mathrm{KV} \text { voltage }\end{array}$ & $P_{220, i}=50$ yuan per $\mathrm{kWh}$ \\
\hline Trading power & $\sum Q_{220, i}=958700000 \mathrm{kWh}$ \\
\hline Average electricity price & $G=388.68$ yuan $/ \mathrm{kWh}$ \\
\hline Loss rate for $220 \mathrm{kv}$ & $\delta_{220}=0.95 \%$ \\
\hline Loss rate for $110 \mathrm{kv}$ & $\delta_{220}=1.15 \%$ \\
\hline
\end{tabular}

Take these parameters into the equation (3), the income decrement caused by implementing straight-powered is shown below:

$$
\begin{aligned}
& \Delta R=\sum_{j=110,220} \sum_{i=1}^{n_{j}}\left(P_{j, i} ' /(1-\delta)-P_{j, i}+F+G\right) \times Q_{j, i} \\
& =\sum_{i=1}^{n_{220}}\left(P_{220, i} /\left(1-\delta_{220}\right)-P_{220, i}+F+G\right) * Q_{220, i}+\sum_{i=1}^{n_{110}}\left(P_{110, i} /\left(1-\delta_{110}\right)-P_{110, i}+F+G\right) * Q_{110, i} \\
& =(50 /(1-0.95 \%)-494.2+388.68) \times 958700+(64 /(1-1.15 \%)-499.2+388.68) \times 1981580 \\
& =-73790329.38 \text { yuan }
\end{aligned}
$$

Thus, the trading income reduces 73790329.38 yuan caused by implementing straightpowered. Besides, the total electricity consumption is 45640 million $\mathrm{kWh}$, and line loss rate is $5.93 \%$.

Therefore, the trading power is calculated as follows:

$$
Q_{\text {total }}{ }^{\prime}=\frac{Q}{\left(1-\delta^{\prime}\right)}=\frac{456.4}{(1-5.93 \%)}=485.17 \mathrm{TWH}
$$


Above all, the straight-powered for big users cause a loss on power Grid Corporation, which is shown as follows:

$$
\Delta P=\frac{\Delta R}{Q_{\text {total }}}=\frac{-73790329.38}{485.17}=-0.00152 \text { Yuan } / \mathrm{kWh}
$$

(2) Analysis on the self-generation power plant

According to the electricity price data for self-generation power plants in Shanxi Province, the main parameters are shown below:

Table 2. Relevant Parameters about Straight-Powered

\begin{tabular}{cc}
\hline Parameters & Values \\
\hline Total electricity consumption of & $\sum_{i=1}^{96} Q_{i}=1.855 \times 10^{10} \mathrm{k} \mathrm{W} \mathrm{h}$ \\
companies owning self-generation & \\
power plants & 96 \\
Purchasing electricity from power & $\sum_{i=1}^{96} Q_{g, i}=1.1542 \times 10^{10} \mathrm{~kW} \mathrm{~h}$ \\
grid corporation & $\sum_{i=36}^{96} Q_{s, i}=5.4965 \times 10^{9} \mathrm{~kW} \mathrm{~h}$ \\
On-grid energy price of self- & $Q_{z}=1.1632 \times 10^{10} \mathrm{k} \mathrm{Wh}$ \\
generation power plant & $\mathrm{B}=0.02 \mathrm{yuan} / \mathrm{kW} \mathrm{h}$ \\
Spontaneous private power & $\mathrm{P}_{\mathrm{i}}^{\prime}=0.02 \mathrm{yuan} / \mathrm{kW} \mathrm{h}$ \\
System backup fee & $0.3447 \mathrm{yuan} / \mathrm{kWh}$. \\
Wheeling cost & \\
Temporary tariff for self-generation & \\
power plant &
\end{tabular}

According to the basic price standard of Shanxi Power Grid, the big industrial electricity price of $110 \mathrm{KV}$ is $P=0.4535 \mathrm{yu}$ an $/ \mathrm{kWh}$, and the average on-grid energy price is $G=0.3857 \mathrm{yu}$ an $/ \mathrm{kWh}$.

Take these parameters into the equation (8), the income decrement caused by implementing self-generation power plants is shown below:

$$
\begin{aligned}
& \Delta R_{z b}=R-\left(R_{1}^{\prime}+R_{2}^{\prime}\right)=\sum_{i=1}^{n}\left[(P-G) Q_{i}\right]-(P-G) \sum_{i=1}^{n} Q_{s}-\sum_{i=1}^{n}\left[\left(B+P_{i}^{\prime}\right) * Q_{z, i}\right]+\sum_{i=1}^{n}\left[\left(G-P_{i}\right) * Q_{s}\right]= \\
& 1.855 \times 10^{10} \times(0.4535-0.3857)-(0.4535-0.3857) \times 1.1542 \times 10^{10}-1.1632 \times 10^{10} \times(0.02+0.02) \\
& +5.4965 \times 10^{9} \times(0.3857-0.3447) \\
& =2.3523 \times 10^{8} \text { yuan }
\end{aligned}
$$

Thus, the trading income reduces by $2.3523 \times 10^{8}$ yuan, caused by implementing selfgeneration power plants.

Namely, the loss on the power grid corporation owning to building self-generation power plants is shown as follows:

$$
\frac{\Delta R_{z b}}{Q_{\text {total }}{ }^{\prime}}=\frac{2.3523 \times 10^{8}}{1.1632 \times 10^{10}}=0.02 \text { Yuan } / \mathrm{kWh}
$$

According to the results above, the straight-powered for big users and self-generation power plant in Shanxi province make the corporation lose 0.00152 yuan per $\mathrm{kWh}$ and 0.02 yuan per $\mathrm{kWh}$, respectively. Obviously, the impact of self-generation power plants is much greater. 


\section{Conclusion}

With the acceleration of the pace of power market reform in China, straight-powered for big users and self-generation power plants, as two ways of opening electricity market, are gradually carried out in various regions. Nevertheless, owning to the reduction of trading power, the operation income would decrease accordingly. This paper established the models to calculate and compare the impacts on operating income of power Grid Corporation after implementing straight-powered for big users and self-generation power plants. The specific conclusions are as follows:

(1) The straight-powered for big users changes the operation mode of power Grid Corporation, which results the changes of total cost, total income and transmission service charge, etc. In addition, the operation income would change as well. Through empirical analysis, we see that the straight-powered for big users in Shanxi province brings a loss of 0.00152 yuan per kWh for power Grid Corporation.

(2) Since the self-generation power plants would permanently occupy the electricity market, the trading power and income would decrease as well. According to the calculation of the example, we see that the self-generation power plants in Shanxi province brings a loss of 0.02 yuan per $\mathrm{kWh}$ for power Grid Corporation.

(3) Based on the comparison of the impacts on operating income in power Grid Corporation after implementing straight-powered or self-generation, we see that the impact from self-generation power plant is much larger than the straight-powered for big users.

\section{Acknowledgements}

This study is supported by the Humanity and Social Science project of the Ministry of Education of China (Project number: 11YJA790217) and the National Natural Science Foundation of China (Project number: 71373076).

\section{Reference}

[1] D. Fang, X. Wang and Y. Zhang, "A Double auction Bayesian model with supplier and demander in open bilateral electricity market", Power system technology, vol. 12, (2003).

[2] K. Rose and J. F. McDonald, "Economics of electricity self-generation by industrial firms", The Energy Journal, (1991), pp. 47-66.

[3] J. A. P. Lopes, F. J. Soares and P. M. R. Almeida, "Integration of electric vehicles in the electric power system", Proceedings of the IEEE, vol. 99, no. 1, (2011), pp. 168-183.

[4] A. J. Wood and B. F. Wollenberg, "Power generation, operation, and control", John Wiley \& Sons, (2012).

[5] A. Monticelli, "Electric power system state estimation", Proceedings of the IEEE, vol. 88, no. 2, (2000), pp. 262-282.

[6] S. Huang and D. Infield, "The potential of domestic electric vehicles to contribute to power system operation through vehicle to grid technology", Universities Power Engineering Conference (UPEC), 2009 Proceedings of the 44th International. IEEE, (2009), pp. 1-5.

[7] J. Bower and D. W. Bunn, "Model-based comparisons of pool and bilateral markets for electricity", The energy journal, (2000), pp. 1-29.

[8] D. Fang, X. Wang and Y. Zhang, "A Double auction Bayesian model with supplier and demander in open bilateral electricity market”, Power system technology, (2003), 12: 000.

[9] H. Song, C. C. Liu and J. Lawarrée, "Nash equilibrium bidding strategies in a bilateral electricity market", Power Systems, IEEE Transactions, vol. 17, no. 1, (2002), pp. 73-79.

[10] J. Bower and D. W. Bunn, "Model-based comparisons of pool and bilateral markets for electricity", The energy journal, (2000): 1-29.

[11] D. Songhuai, Z. Xinghua and M. Lu, "A novel nucleolus-based loss allocation method in bilateral electricity markets", Power Systems, IEEE Transactions, vol. 21, no. 1, (2006), pp. 28-33.

[12] R. Liang, H. Xu and H. Xia, "Calculation and analysis of influence made by large consumers directpurchasing on the profit of power companies", Power Demand Side Management, (2005), 6: 011.

[13] H. Xia, H. Xu and R. Liang, "Discussion on the problems existing in the experimental unit of large consumers direct-purchasing", Power Demand Side Management, (2006), 4: 009. 


\begin{abstract}
Authors
Huiru Zhao received the Ph.D. in technological economics from North China Electric Power University.

From 1988 to 2014, she taught at North China Electric Power University. Her current research interests include Electric power economics and management, technological economics, and energy management. She has applied for several fund projects, such as the national natural fund and Humanity and Social Science project of the Ministry of Education of China.
\end{abstract}

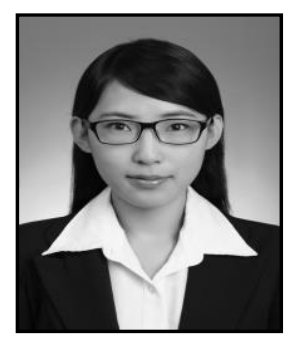

Nana Li received the master degree in technological economics from North China Electric Power University. And she is reading for the Ph.D. in energy management in North China Electric Power University.

From 2012 to 2014, she studied at North China Electric Power University. Her current research interests include Electric power economics and management, technological economics, and energy management. 